\title{
QUITANDEIRAS CONTEMPORÂNEAS: A INVISIBILIDADE FEMININA NA GASTRONOMIA VERNACULAR
}

\section{CONTEMPORARY QUITANDEIRAS: THE FEMININE INVISIBILITY IN VERNACULAR GASTRONOMY}

\author{
Ana Madalena Vieira de Albuquerque Belo Costa ${ }^{1}$ \\ Maria Alice Vasconcelos Rocha ${ }^{2}$
}

\begin{abstract}
Resumo
A mulher, a comida, o trabalho e a cidade e suas interrelações, sinalizando uma invisibilidade feminina, é o cerne deste estudo que se debruça sobre o cotidiano vivenciado por mulheres que produzem e comercializam alimentos nas vias públicas do Recife. Foram analisadas as estratégias e atividades desenvolvidas pelas atrizes sociais, que ocupam o espaço urbano e constroem significados ao reproduzir uma condição ancestral de labor a céu aberto, o arruar e mascatear em suas quitandas contemporâneas nas ruas dos bairros de São José e Santo Antônio, na cidade do Recife, em Pernambuco, Nordeste do Brasil. A metodologia desta pesquisa inicia-se com a busca da historicidade das quitandas no Brasil, seguida da seleção do corpus a ser observado qualitativamente. Objetiva-se apresentar as redes de relacionamentos familiares destas mulheres comerciantes ambulantes e entender como se relacionam com a estrutura subjetiva que permeia a ocupação e uso de vias urbanas. A coleta realizada com entrevistas semiestruturadas da investigação participante trouxe subsídios à análise dos conteúdos em categorias e, conclusivamente, percebese uma histórica e persistente invisibilidade feminina.
\end{abstract}

Abstract Women, food, work, city and their interrelations, flagging a female invisibility, is at the core of this study which deals with the everyday life experienced by women who produce and sell food today on streets in the city of Recife. The strategies and activities carried out by these social actresses were observed as they occupy the urban space and construct meanings when playing an ancestral condition of labour, peddling in the street markets the neighbourhoods of São José and Santo Antônio in the city of Recife in Pernambuco, north-eastern of Brazil. The methodology of this research begins with the search of the historicity of the Brazilian quitandas. Then, the selected corpus was observed qualitatively. The goal was to present the family relationships of these itinerant merchants and to understand how women relate to the subjective structure that permeates the occupation and use of urban streets. The data were collected by semistructured interviews, participant research brought content analysis subsidies into categories. Conclusively, the research realizes a persistent contemporary and historical female invisibility.

Palavras-chave: Comida de rua. Cotidiano. Mulheres. Key-words: Street food. Daily life. Women. Work.

\footnotetext{
${ }_{1}^{1}$ Arquiteta e urbanista graduada pela UFPE, Gastrônoma pela faculdade SENAC/PE, Pós-graduada pelo CEDEP Business School, com MBA em Gestão Empresarial, Mestre pela UFRPE em Consumo e Desenvolvimento Social. $2 \mathrm{PhD}$ in Fashion Design - University for the Creative Arts / University of Kent (2007); Mestre em Engenharia de Produção pela Universidade Federal de Pernambuco (1999); Especialista em Comunicação de Moda pela Universidade Federal do Rio de Janeiro (1992); Estilista de Moda em Confecção Industrial pelo Senai CETIQT-RJ (1992); Arquiteta pela Universidade Federal de Pernambuco (1989) e professora do Departamento de Ciências Domésticas da Universidade Federal Rural de Pernambuco.
} 
Trabalho 


\section{INTRODUÇÃO}

Estudar o cotidiano possibilita revelar hábitos e costumes de grupos humanos. O corpus pesquisado neste trabalho delimita-se em mulheres que atuam como ambulantes na produção e comercialização de gêneros alimentícios no centro histórico recifense, inserido hoje nos bairros de Santo Antônio e São José.

Conhecer a mulher que produz alimentos para comercialização em vias públicas no centro histórico recifense é enxergar a pobreza e o trabalho doméstico; é entender seus arranjos familiares, arranjos que as possibilitam trabalhar fora de casa. É pensar na cozinha domiciliar como um espaço laboral na rede que permeia a relação de produção e distribuição de produtos alimentares, na medida em que este pode ser o laboratório possível a estas mulheres. É pensar no silenciamento feminino, no não protagonismo feminino no âmbito da gastronomia, seja gourmetizada ou vernacular, nas discrepâncias numéricas de remuneração entre os gêneros em atividades laborais semelhantes.

Segundo Rego e Pinzani (2013), na tradição intelectual brasileira, não é comum tratar dos sujeitos considerados desempregados estruturais, "dos destituídos de voz". O texto de Vozes do Bolsa Família aborda questões ligadas à autonomia financeira e cidadania de mulheres beneficiadas pelo programa.

E por que visibilizar as quitandeiras contemporâneas? Qual a importância de estudar este cotidiano feminino? Em Cotidiano e Poder, Dias (1984) apresenta a situação cotidiana das mulheres nas diversas camadas sociais da capital paulistana no século XIX. Em determinado ponto, ela aborda a atuação na produção e comercialização de alimentos e gêneros correlatos através da mão de obra feminina. Entre os aspectos apresentados pela autora, destaca-se a importância de referendar historicamente a presença feminina e as interfaces da mulher urbana no século XIX nas vias paulistanas, abrindo com seu relato o apetite para se buscar a mulher ancestral que atuou e na mulher contemporânea que atua nas ruas recifenses hoje.

Problematizar a atividade diária de comercialização de alimentos por mulheres possibilita entender como se dá a sua articulação no seio do emaranhado urbano, quais são suas estratégias e táticas de permanência e sobrevivência. Busca-se, então, ouvir a voz da mulher que comercializa alimentos nas vias públicas recifenses.

Se no Brasil colonial, as quitandeiras teimavam em permanecer na cena urbana como única forma de subsistência na malha social estabelecida à época, como se dá hoje na gastronomia vernacular? Qual o tom e o volume da voz das quitandeiras contemporâneas? 
Quais são os saberes que são reproduzidos e que sabores elas trazem nas suas panelas e frigideiras? Como se constituem suas famílias e redes de relacionamento?

Em suma, a pergunta de pesquisa deste trabalho é: Persiste uma invisibilidade histórica feminina nesta atividade? Adicionalmente, busca-se questionar: Como vivem e trabalham as mulheres que produzem e comercializam comidas de rua no entorno do Mercado de São José?

A partir do problema de pesquisa aventado, o da invisibilidade feminina que atua no segmento de negócios da gastronomia, estabelece-se como objetivo geral nesta pesquisa: estudar o cotidiano de mulheres ambulantes que produzem e comercializam comida de rua no centro da cidade do Recife. Adicionalmente, tem-se como objetivos específicos: (1) Entender como se dá a sua articulação no seio do emaranhado urbano, (2) Quais são suas estratégias e táticas de permanência e sobrevivência e (3) Ouvir a voz da mulher que comercializa alimentos nas vias públicas recifenses. Com isto, pretende-se, a partir da publicização destes dados, uma maior visibilidade destas personagens urbanas.

A fundamentação teórica desta pesquisa delimitou-se em eixos de interesse e correlação sob a ótica feminina, estruturando-se em dois tópicos: o primeiro, contemplando a historicidade da atividade mercantil urbana contextualizada em Recife com: feiras mascates, tabuleiros e comida de rua; e o segundo, buscando trazer as teorias das vivências femininas familiares de formas abrangentes em família, mulher e cotidiano.

\section{FEIRAS, MASCATES, TABULEIROS E COMIDA DE RUA}

São múltiplos os significados da alimentação, do coletivo cultural à memória gustativa pessoal. Existem momentos e lugares próprios para cada atividade, existe o alimentar-se no lar, e existe o alimentar-se em público. Nesta perspectiva se insere, além dos bares, restaurantes e lanchonetes, os espaços das vias públicas, como as feiras e mercados, onde se prepara e comercializa alimentos; são as denominadas comidas de rua.

O Recife, por sua situação geográfica de cidade portuária, em sua origem, possuía um grande contingente de profissionais dedicados à atividade comercial. Nos anos 1670, após o período em que o Recife foi ocupado pelos holandeses (1630-1654), o número de mascates era tão grande que a concorrência entre comerciantes em lojas e os vendedores ambulantes fez com que a Câmara autorizasse a comercialização, pelos ambulantes, apenas de "fitas, linhas e outras coisas de menor importância" (GOULART, 1967, p. 112).

No ano de 1711, compreendido como Alterações Pernambucanas, a cidade passa a ser designada de forma jocosa pela nobreza olindense de cidade dos mascates. Segundo Goulart 
(1967), a origem da denominação "mascate" vem da cidade de mesmo nome, dominada pelos portugueses entre 1507 e 1559, localizada no litoral sul do Golfo de Omã. A região tornou-se um atrativo e próspero centro de mercadores das mais variadas origens. Ao regressarem a Portugal, esses comerciantes eram denominados de mascates. Surge daí esta denominação daquele que exerce a atividade de comércio sob a forma itinerante.

O século XIX traz ao perímetro urbano a figura do vendedor ambulante, via de regra um escravo ou escrava liberto, que mantinha com a comercialização nas ruas um modo de ganho de vida, um paralelo à atividade dos mascates, comerciantes que exercem também a atividade de "mascatear". O ambulante é uma presença marcante no cotidiano urbano, trazendo significados ligados ao comércio e ao varejo.

O atual bairro de São José tinha como nome de origem em suas cercanias de Mercado do Peixe e teve sua ocupação originalmente marcada pelo comércio de gêneros de abastecimento alimentícios, permanecendo até hoje com esta forte temática.

Nesta medida, as quitandeiras em muito se assemelham ao comércio das feiras descritas por Braudel (1996), que dialoga com Pantoja (2008), descrevendo a similaridade das feiras da atualidade com os arranjos comerciais das quitandeiras do Brasil-Colônia. O autor detalha que se vendia de um tudo nas feiras, artesanatos, alimentos; era um lugar de encontro e de negócios.

Antes de desembarcarem no Brasil, as quitandas eram uma modalidade de comércio tipicamente africana espalhada por todo o continente, mais especificamente em Angola. Estas quitandeiras abasteciam as cidades litorâneas e até os navios negreiros. Nos primórdios da comercialização de comidas de rua no Brasil, esta atribuição era das mulheres negras africanas e seus tabuleiros de alimentos. Bonomo (2014), em seu relato, ressignifica esta atividade como de grande valor no posicionamento social e histórico da mulher no contexto colonial, Esta atividade comercial era essencialmente desenvolvidas por escravas cativas e escravas de ganho, negras forras ou libertas, mulheres empobrecidas, que tinham no comércio ambulante sua fonte de sobrevivência e de resistência às poucas oportunidades laborais femininas à época: a comercialização de alimentos e bebidas nas vias das principais cidades do Brasil-Colônia, a exemplo de Rio de Janeiro, São Paulo, Salvador e Minas Gerais.

Apesar de Recife ter sido durante séculos a capital econômica do Brasil-Colônia com a cultura da cana-de-açúcar, ainda não foi possível encontrar registros significativos acerca da atividade comercial das quitandeiras nas ruas da capital pernambucana à época. Faz parecer que a mulher enquanto sujeito produtor e fomentador de renda e negócios inexistiu neste período. Poucos relatos apontam para a presença urbana destas mulheres. E encontram-se 
breves relatos apenas em nível de sítios rurais, referendando a participação feminina nos movimentos quilombolas nordestinos.

\section{INVISIBILIDADE FEMININA}

Análises iniciais sob a perspectiva antropológica conceituam família a partir das estruturas de parentescos, filiações e representações de organização tribal. Tais referendos foram utilizados por Marx em Formações Econômicas Pré-Capitalistas (1973), na tentativa de entender as condições que possibilitaram o estabelecimento do modo capitalista de produção, e por Engels na perspectiva do materialismo histórico em A Origem da Família, da Propriedade e do Estado (1981), buscando a origem das formações familiares e suas mudanças no processo de estruturação da sociedade.

Em terras brasileiras, vem de Gilberto Freyre (1933) em Casa Grande e Senzala, a afirmação de que os primeiros relatos sobre as famílias foram dos comerciantes e colonizadores, viajantes em andanças pelo Brasil-Colônia. Registros que, de forma geral, impregnados da expressão do colonialismo e etnocentrismo, mostram uma assimetria de poder, com traços regionais, na tradução desta visão, cultural, econômica e política. $\mathrm{Na}$ contemporaneidade, Bruschini (1990) alerta para a naturalização da família, tanto em uma visão de senso comum quanto na reflexão científica.

Poderíamos, então, a partir de Bruschini (1990), conceituar a família, como sendo um grupamento de indivíduos ligados por consanguinidade, adoção e laços socialmente reconhecidos como o casamento e as uniões estáveis, organizados em núcleos de reprodução social. Seria válido dizer ainda que, nas famílias, as relações são estabelecidas pelos atos da procriação e do consumo, sendo um posto privilegiado, nas quais se dão a divisão sexual do trabalho e a consequente delimitação do grau de autonomia ou subordinação das mulheres.

Neste contexto de dificuldade de fontes históricas centrais, Wadi (1997) cita Dias (1984) em Quotidiano e Poder em São Paulo no século XIX, obra em que a autora relata que, para reconstruir o cotidiano do ganha-pão de mulheres pobres, precariamente documentado nas fontes escrita, se deparou com dificuldades em adquiri-las.

Faz-nos pensar em uma "invisibilidade feminina" na sociedade açucareira patriarcal, invisibilidade esta, citada por Bruschini (1990) em seu livro, Mulher, Casa e Família Cotidiano nas Camadas Médias Paulistanas: "Às mulheres é conferida uma invisibilidade, desconsiderando-se suas atitudes diante do consumo e de seu comportamento como dona-decasa, decorrentes de sua cultura familiar ancestral" (p.91). Ela cita ainda Bourdieu (1979), 
quando este alerta para a necessidade de analisar e considerar a situação e a classe à qual pertence cada um dos cônjuges em uma pesquisa realizada pelo DIEESE em 1981, com o intuito de investigar o "Padrão de Vida, Emprego e Desemprego na Grande São Paulo" em 15 famílias de classe média paulista à época.

\section{FAMÍLIA, MULHER E COTIDIANO}

Mas, e a mulher? Em quais contextos ela se insere nesta narrativa? No conceito de gênero definido por Alves e Pitanguy (1985) é apresentado como uma construção sociocultural, que atribui ao homem e à mulher papéis diferentes dentro da sociedade e depende dos costumes de cada lugar, da experiência cotidiana das pessoas, bem como da maneira como se organiza a vida familiar e política de cada povo. Essa construção social serve como orientador quanto às características formadoras de cada gênero, no âmbito geral, definindo o feminino como o paciente, frágil, emotivo, delicado, sedutor e belo; e o masculino como o forte, rude e agressivo. Moreira (2012) e Carloto (2001) contribuem com a ideia de que as atividades masculinas são distintas das femininas em espaços produzidos pelas esferas domésticas e públicas. Cada uma destas constitui-se num espaço pertencente a um dos gêneros, difícil de sobreporem.

Durham (1983) e Bruschini (1990) concordam que as evidências antropológicas fornecem subsídios para afirmar que todas as sociedades se organizam a partir da divisão sexual do trabalho, tendendo a uma separação da vida social (público), atribuída ao masculino, e da vida doméstica e feminina por excelência. Estas considerações partem de ideias construídas culturalmente a partir de referenciais biológicos e sobre a tendência da espécie humana em prolongar a dependência das crias em relação às mães: “...esta divisão define como feminina a esfera privada, ligada à reprodução e à criação dos filhos. Em contrapartida, a esfera complementar, masculina, estaria associada à política, à guerra e à caça" (DURHAM,1983 apud BRUSCHINI, 1990, p.32).

Para entender o sentido e conceito de família, é importante contextualizar o momento histórico, político e seus interesses intrínsecos. Os elementos: história, sociedade e economia, de forma geral, determinam o modelo de família e, desta forma, não se pode falar em família, mas em famílias e, nesta medida, em arranjos familiares.

De acordo com dados do IBGE Brasil (2015), entre 2004 e 2014 o percentual de lares chefiados por mulheres cresceu 67\%, em que 11,4 milhões de mulheres assumiram a liderança de suas famílias. É válido ressaltar que este aumento das mulheres enquanto pessoa de 
referência nos domicílios está relacionada ao maior acesso delas ao mercado de trabalho. Entretanto, conforme ressalta Vettorazzo e Villas Bôas (2015), a despeito do crescimento feminino nos postos de trabalho, a diferença de rendimentos entre os gêneros persiste. $O$ rendimento médio das mulheres em atividades formais foi de $R \$ 1.763,00$ em 2014, valor $R \$$ 530,00 menor que o dos homens.

Outro indicador que enfatiza a desigualdade entre os gêneros e norteia a importância do trabalho feminino no lar é a que quantifica o número de pessoas que, mesmo com atividades laborais fora do lar, realizam os afazeres domésticos: cozinhar, limpar a casa e lavar as roupas. Para Certeau (1996), entender o cotidiano é enxergar a face comum e ordinária dos atores e atrizes sociais, que ele chama de o "homem ordinário", o "herói comum" e anônimo, atores sociais que balbuciam "o murmúrio das sociedades".

\section{PROCEDIMENTOS METODOLÓGICOS}

Esta pesquisa optou por uma aproximação personalizada, traduzida em um estudo observacional com investigação participante junto ao grupo pesquisado, utilizando-se da entrevista semiestruturada como ferramenta de coleta de dados e fundamentando-se nas teorias metodológicas da pesquisa social em Richardson (2012) para a estruturação do instrumento de coleta de dados; em Bardin (2016) e em Alves e Silva (1992) para a compreensão e sistematização dos conteúdos adquiridos junto às entrevistadas.

A pesquisa estruturou-se com uma abordagem qualitativa, considerada por Denzin e Lincoln (2006) uma ação interpretativa e localizada que situa o observador em determinado contexto, possibilitando ao pesquisador visibilizar o universo vivenciado pelos sujeitos da ação, trazendo à tona suas representações e significados. Está ainda respaldada em Minayo (2002), Godoy (1995) e Gil (1999), visto que este estudo trata de um fenômeno das Ciências Sociais, a observação do cotidiano vivenciada por mulheres comerciantes de comidas de rua.

Baseada em Godoy (1995), a obtenção dos dados tornou-se viável acerca das relações entre os sujeitos, o lugar e seus processos interativos, possibilitando a esta pesquisa observar e compreender os fenômenos sob a perspectiva dos envolvidos. Nesta medida, Gil (1999, p.94) corroborou, afirmando que os "métodos de pesquisa qualitativa estão voltados para auxiliar pesquisadores a compreenderem pessoas e seus contextos sociais, culturais e institucionais".

Considerando sempre os objetivos desta pesquisa, buscou-se, ainda, as tipologias exploratória e descritiva. De acordo com Gil (1999, p.43), a pesquisa exploratória tem como meta trazer informações significativas acerca dos assuntos a serem investigados, a delimitação 
do tema pesquisado, deixar claro os objetivos e a formulação das hipóteses. Neste sentido, foi fundamental a busca dos marcos teóricos sobre os pilares da pesquisa, que se definiram por questões ligadas ao gênero feminino, possibilitando aprofundar o conhecimento acerca da historicidade dos conceitos da percebida invisibilidade histórica feminina. Assim, as questões se relacionam ao trabalho e ao posicionamento profissional entre gêneros, à formação da malha urbana e da dinâmica de ocupação contida no cenário pesquisado, às relações tecnológicas da produção e transformação do alimento e do alimentar-se.

A flexibilidade no planejamento possibilitou considerações e multiplicidade dos aspectos do corpus estudado. Após o levantamento bibliográfico buscou-se estruturá-lo e partiu-se para as entrevistas com sujeitos familiarizados com o problema pesquisado, possibilitando uma análise compreensiva de exemplos. Justificando-se com os objetivos que se pretendeu ao explorar e descrever a situação socioeconômica destas mulheres.

Para conhecer e descrever as entrevistadas, bem como interpretar suas inter-relações e realidade do cenário estudado, optou-se por Gil (2008, p. 46), quando afirma que esta "[...] tem como objetivo primordial à descrição das características de determinada população ou fenômeno ou, então, o estabelecimento de relações entre as variáveis".

As pesquisas descritivas são, juntamente com as exploratórias, as que habitualmente são realizadas pelos pesquisadores sociais, preocupados com a atuação prática no cotidiano.

\section{Locus e Corpus da pesquisa}

A investigação se deu no cenário do entorno de um dos vinte e quatro mercados públicos do Recife, o Mercado de São José, situado no bairro de mesmo nome e inaugurado em 07 de setembro de 1875, o mais antigo mercado público do Brasil. É o primeiro edifício préfabricado em ferro no país, com a mesma estrutura neoclássica dos mercados europeus do século XIX.

$\mathrm{Na}$ atualidade, os mercados públicos são tratados como símbolo da cultura local, onde se encontram não somente os produtos característicos do cotidiano, como a personificação da perpetuação de hábitos e costumes ancestrais de alimentação e insumos. Desde a década de 1990, alguns mercados, a exemplo do mercado da Cantareira, em São Paulo capital, e do mercado A Ver o Peso, em Belém, passaram por processos de revitalização com obras formais e estruturais, no intuito de atrair, além da população local, o público flutuante em viagens turísticas, algumas delas de cunho gastronômico 
Nóbrega (2008) traz uma preciosa cronologia ocupacional do sítio onde hoje se insere o Mercado de São José, definido nesta pesquisa como marco de referência. Da denominação de Sítio dos Coqueiros, depois Largo da Ribeira do Peixe, passa a ser, em meados do século XIX, objeto de interesse do então governador de Pernambuco Don Tomás José de Melo, que determina a construção do conjunto de barracos onde se comercializavam frutas, verduras e peixes como forma de ordenação destas atividades. Só em 1871, a Câmara de Vereadores do Recife dá início a formatação do Mercado como o conhecemos, passando por várias requalificações físicas e estruturais, chegando a atualidade com sua persistente vocação de centro de abastecimento e distribuição de produtos alimentares. Nesta medida, o Mercado de São José afigura-se ainda como polo de interesse histórico e turístico.

$O$ corpus desta pesquisa define-se nas mulheres que atuam formal e informalmente na produção e comércio de alimentos nas ruas de entorno do Mercado Público de São José, na cidade do Recife. Inicialmente pretendia-se um número mínimo de dez comerciantes a serem entrevistadas, entretanto, a realidade vivenciada se apresentou com uma certa dificuldade em atingir o número previsto, levando-se em conta o critério seletivo do recorte no corpus.

Para fazer o recorte no corpus da pesquisa, foram definidos dois critérios: 1) a comerciante e/ou produtora deveria ser a titular e proprietária do negócio de alimento; e 2) a tipologia das preparações alimentares produzidas e comercializadas pelos sujeitos da pesquisa precisaria estar inserida nos conceitos e bases da produção, técnicas e insumos que remetessem à culinária e saberes ancestrais brasileiros, oriundos da miscigenação das culturas, indígenas, africanas e portuguesas, contemplando o contexto da gastronomia nordestina, tais como a tapioca, o caldo de cana e os corriqueiros "pratos feitos", na linguagem popular.

$\mathrm{Na}$ cozinha tradicional nordestina, esta combinação nutricional compõe-se de: feijão preto ou mulatinho, arroz branco, uma proteína de origem animal, acompanhados de salada pernambucana (alface, tomate, cebola e, às vezes, pimentão, regados em vinagre de álcool). Esses alimentos eram largamente consumidos nos boxes e barracas de feiras populares.

\section{Procedimentos de coleta de dados}

Em relação à estruturação de coleta de dados, a pesquisa se configurou do tipo bibliográfica com levantamento histórico acerca de como esta atividade mercantil, o das comerciantes de comida de rua, teve seu início e se desenvolveu no Brasil, especificamente em Recife, até a contemporaneidade. No primeiro momento foi realizado o estado da arte 
sobre o tema, percebendo-se uma lacuna bibliográfica na historicidade desta atividade exercida por mulheres pernambucanas no que tange à comercialização de alimentos em vias públicas.

O segundo momento caracterizou-se por uma observação participante, definida por Becker (1994), como a forma com que o pesquisador coleta dados, estando inserido no grupo ou comunidade e observando o comportamento das pessoas em seus cotidianos. As idas periódicas a campo buscaram caracterizar-se por um caminhar respeitoso dentro da comunidade observada, levando-se em conta futuras questões éticas relacionadas às publicações de dados coletados sobre a comunidade que recebe o observador em seu meio.

Para tanto, foi necessário ver e ouvir com atenção, buscando registrar na medida do possível as informações apresentadas, considerando que esta tomada de notas acontece simultânea ao acontecimento dos atos. A escolha pela abordagem técnica da aplicação de entrevistas semiestruturadas objetivou uma aproximação mais efetiva, uma forma de criar um traço de identificação da pesquisadora com as mulheres pesquisadas, em uma forma mais dialogada de ouvir a fala das interlocutoras.

Gil (2008) conceitua entrevista como uma interação social, uma forma de coleta de dados, uma técnica na qual o investigador se apresenta ao investigado realizando perguntas com finalidade de obtenção de informações para a investigação, podendo obter desta forma, informações sobre vários aspectos da vida social do investigado.

A estratégia de aproximação foi definida pela pesquisadora em posicionar-se como consumidora dos produtos comercializados pelas quitandeiras. $O$ primeiro passo foi perguntar quais produtos estavam à venda e os preços praticados por elas. O segundo foi a escolha de algum item a ser consumido. O terceiro passo foi a entabulação da conversa acerca das práticas cotidianas no ponto de venda. O quarto foi a apresentação da pesquisa em linhas gerais, falando nome da pesquisadora, nome da instituição: Universidade Federal e Rural de Pernambuco (UFRPE), e a intenção: observar e registrar a vida cotidiana de mulheres que trabalham a céu aberto nas ruas dos bairros de São José e Santo Antônio, no entorno do Mercado Público de São José.

No entanto, estas aproximações apresentaram algumas dificuldades logísticas. De forma geral, as entrevistas foram realizadas em pé nas ruas e calçadas, durante a execução das atividades desenvolvidas pelas entrevistadas, embora tenha-se tomado o cuidado em não causar atrapalho ao atendimento dos demais consumidores. Outro ponto de dificuldade, 0 clima, visto que as entrevistas precisavam ser em horário de funcionamento dos seus pontos comerciais, entre as $11 \mathrm{~h} 00$ e 15h00, horário previsto para o almoço. Neste intervalo, as 
temperaturas chegavam a $38^{\circ} \mathrm{C}$, e em alguns pontos de comércio não havia proteção de guarda-sóis.

Autores como Gil (2008) e Richardson (2012) sugerem a aplicação do recurso prévio do pré-teste, como forma de avaliação da eficácia na aplicação das perguntas da entrevista e prevenção de possíveis incorreções.

A título de pré-teste, foram feitas abordagens na Rua de Santa Rita, com duas ambulantes tapioqueiras. Neste primeiro contato, ficaram evidentes algumas limitações que a pesquisa encontraria: as falas do pré-teste e das entrevistas inicialmente seriam gravadas em smartphones para posterior transcrição; entretanto, a realidade percebida pela pesquisadora no entorno urbano estudado mostrou-se mais arriscada sob o ponto de vista da segurança pessoal, em decorrência da violência urbana. Desta forma, optou-se por registrar as respostas de próprio punho pela entrevistadora.

Com base no objetivo geral: estudar o cotidiano das mulheres que produzem e comercializam comidas de rua no entorno do Mercado de São José, as entrevistas foram estruturadas dentro nas seguintes temáticas: (1) Origem; (2) Arranjos familiares; (3) Relações de vizinhança.

\section{Sistematização dos dados}

Após a captação das falas dos sujeitos observados em campo, realizou-se a transcrição do material captado pela pesquisadora, para que então fosse iniciado o processo de sistematização dos dados.

Mesmo com a dificuldade em registrar a fala das entrevistadas em gravações eletrônicas, o que traria mais subsídios à pesquisa, a pesquisadora procurou ater-se à linha de pensamento abordada por Alves e Silva (1992), da análise qualitativa. Adicionalmente, Fernandes (1991) define a análise qualitativa por uma busca, apreensão de significados na fala dos sujeitos contextualizada em seu ambiente de inserção e delimitada pela abordagem teórico conceitual do pesquisador

Assim, esta pesquisa focou sua sistematização de dados, dentro da observação constante do problema de pesquisa e concretização dos objetivos almejados.

\section{Análise de conteúdo}


O processo de tratamento dos dados deu-se pela análise dos conteúdos nos discursos proferidos pelas entrevistadas, as quitandeiras de comidas de rua recifenses. Optou-se, desta forma, pela análise do conteúdo adquirido, tomando-se Bardin (2011, p.49) como referência: “a análise de conteúdo procura conhecer aquilo que está por trás das palavras sobre as quais se debruça".

Nesta medida, a análise de conteúdo tentou compreender a oralidade dos atores em seus ambientes de atuação, em um dado momento, com contributos exemplificados na forma como estas mulheres se utilizaram da fala para expressar suas realidades cotidianas. A partir das definições de análise do conteúdo apresentadas por Richardson (2012) conclui-se que, como técnica de pesquisa, possui características metodológicas definidas em: objetividade, sistematização e inferência.

Para Richardson (2012), a objetividade se traduz em deixar claras as regras e procedimentos que serão utilizados nas etapas da análise dos conteúdos. Assim, é necessário definir quais processos decisórios o pesquisador precisará escolher, quais categorias serão utilizadas e quais os critérios serão utilizados para registrar e codificar o conteúdo. Ao sugerir estas etapas, o autor acredita na possibilidade de minimização da subjetividade e em uma maior utilização fidedigna da análise de conteúdo dos documentos, dos registros e, no caso em questão, das falas destas quitandeiras.

$\mathrm{Na}$ presente pesquisa, buscou-se trazer a análise categorizada, na qual se espera que o pesquisador adote critérios de homogeneidade, ao não misturar critérios de classificação, de exaustividade, utilizando todo o material colhido e transcrito, e por fim, de exclusão, em que se espera que não haja repetição de um mesmo elemento em mais de uma categoria (RICHARDSON, 2012).

Quanto à sistematização, esta diz respeito à inclusão ou exclusão dos conteúdos ou das categorias do material coletado, tomando-se por base para este procedimento normas claras e consistentes, objetivando testar hipóteses, e, nesta medida, analisar todo e qualquer registro colhido durante a fase de coleta de dados, estando os dados a favor ou contra tais hipóteses.

A inferência, tanto para Bardin (1979) como para Richardson (2012), "refere-se à operação pela qual se aceita uma proposição em virtude de sua relação com outras proposições já aceitas como verdadeiras" (BARDIN, 1979, p.45). De acordo com estes dois autores, a descrição é a primeira etapa da análise, sendo a interpretação a fase final, restando à inferência o posto de ação intermediária, que une as duas etapas. Objetivamente, cita-se Laswell et al. (1952, p.12 apud Richardson, 2012, p.224) ao definir inferência: "quem diz o quê, a quem, como e com que efeito?". 
Esta pesquisadora acredita e, nesta medida, concorda com Bardin (1979) que antes de ser uma leitura de palavras, a análise de conteúdo traz uma oportunidade ao pesquisador de adentrar de forma sistemática e multidisciplinar nos campos da História, Sociologia, e da Psicologia, na busca dos significados dos conteúdos que thes são ofertados pelos pesquisados.

\section{Ética na pesquisa social}

De acordo com Diniz e Guerreiro (2008), o Termo de Consentimento Livre e Esclarecido por escrito é anterior à fase de coleta de dados e uma exigência em termos éticos da pesquisa social, em quê, via de regra, utilizam-se técnicas de entrevistas, cuja cena de pesquisa é formalmente definida, permitindo a apresentação do termo antes do início da entrevista, a partir da qual se originará a interação social entre pesquisador e participante.

Nesta pesquisa enxergaram-se algumas situações limitantes à aplicação do TCLE: 01- o cenário das entrevistas a céu aberto, na localidade onde as entrevistadas exercem sua função de produzir e comercializar alimentos de rua; 02- parte das entrevistadas fazerem parte da população iletrada da sociedade; 03- a não disponibilidade de tempo por parte das entrevistadas, tendo em vista estarem em seus horários de atividade, durante os encontros entre a pesquisadora e as pesquisadas; 04- a pouca segurança explicitada por parte de algumas entrevistadas, por estarem publicamente verbalizando situações cotidianas de riscos físicos inerentes à atividade em via pública. Pelo exposto, esta pesquisadora optou por um consentimento verbalizado por parte das entrevistadas.

\section{ANÁLISE E DISCUSSÃO}

A partir dos dados coletados nas entrevistas semiestruturadas da investigação participante, possibilitou-se apresentar o perfil humano das quitandeiras e as categorias delimitadas, a partir da fala das entrevistadas, ficando, assim, delimitadas: família e convivências; trabalho e a renda; e o lar a sobrevivência na rua, interpretadas a partir da análise dos conteúdos obtidos. Neste artigo, entretanto, abordaremos os resultados concernentes às relações familiares de convivência e interdependências. 


\section{As quitandeiras contemporâneas}

As falas das quitandeiras urbanas entrevistadas narram caminhos de vida parecidos. Caminhos marcados por muita dificuldade financeira, em que faltam oportunidades, informação e acesso à educação. Em sua maioria discorrem sobre a necessidade de trabalhar ainda muito cedo e da dificuldade em conciliar o estudo na idade infanto-juvenil com o trabalho.

Durante as entrevistas, só duas delas dividem a vida e a moradia com um companheiro; quatro são viúvas e vivem sozinhas e três são divorciadas. Uma delas vive e sustenta um filho maior de idade e a outra compartilha a casa e o trabalho na rua com uma filha de 18 anos, ainda estudante do Ensino Fundamental. Uma delas esteve envolvida em mais de uma relação marital, tendo filhos de diferentes homens. O número de filhos varia: vai de nenhum a sete filhos por entrevistada.

Uma parte significativa começou a trabalhar muito jovem, por volta dos oito anos de idade, para ajudar no sustento da família; outras iniciaram o trabalho nas ruas após tornaremse viúvas ou por abandono por parte dos companheiros. Algumas relatam gostar do trabalho que exercem, entretanto, de forma geral, não conseguem mensurar quanto ganham, nem quanto investem em insumos.

Esta dificuldade em afirmar os valores perfeitos com a atividade abre espaço para questionamentos que nos leva à suposição de que inexiste um conhecimento por parte destas mulheres das questões ligadas à economia e empreendedorismo, vindo de encontro à pouca escolaridade encontrada entre as quitandeiras. O grau de educação formal entre elas é baixo; três destas entrevistadas não frequentaram a escola, uma outra parte das pesquisadas abandonou os estudos antes de completar o ensino fundamental e apenas duas das entrevistadas possuem o ensino médio concluso.

A observância acadêmica sobre empreendedorismo cresce a partir da década de 1980, segundo Gomes (2004). Entretanto, ainda segundo ela, teóricos como Cantillon (1680-1734), Say (1767-1832) e Schumpeter (1883-1950) já versavam sobre o tema. Buscar o empreendedorismo é trazer alternativas ao modelo de ganhos e remunerações por empregos tradicionais, cujas oportunidades de acesso apresentam-se escassas no atual contexto econômico. Desta forma, o empreender mesmo que em nível de pequeno comércio se faz necessário a estas mulheres que precisam manter-se economicamente ativas.

Quanto à faixa etária, a idade das entrevistadas variou de 43 a 65 anos. Ao iniciar esta pesquisa, imaginou-se encontrar um perfil de idade um pouco menor, tendo em vista o nível de esforço despendido com atividades desenvolvidas em cozinhas de produção de alimentos em 
escala comercial, bem como a aridez que se pode observar em atividades laborais exercidas em meio às vias urbanas da maioria das grandes cidades.

\section{Quitandeira 01}

"Morena", uma senhora vistosa e falante, com 54 anos, viúva há apenas sete meses à época da entrevista. É uma mulher vaidosa, de boa conversa, apresenta-se maquiada e com unhas grandes e pintadas de cores fortes, aparentemente empoderada e orgulhosa dos filhos que gerou: "Tenho dois filhos formados e tem pós-graduação, são independentes" e diz que o marido criou o equipamento que alguns fornecedores de coco ralado utilizam, o raspador de coco elétrico. Tem dois filhos que não moram com ela (30 e 26 anos) e três netos. Estudou até a terceira série do ensino fundamental; é natural de Recife, reside no bairro de São José. Mora sozinha, a mãe é independente economicamente dela e mora em Taquaritinga do Norte, interior de Pernambuco. Comercializa insumos para o preparo da tapioca: goma de mandioca e coco ralado. Atua na Rua da Praia, no bairro de São José.

\section{Quitandeira 02}

"Lena", uma senhora miúda e aparentemente tímida, de fala mansa e modos recatados, que deixa antever na sua mansidão uma personalidade forte. Ao longo das minhas idas a campo, ela sempre me cumprimentava e quando via meu marido circulando pala Rua da Praia sem mim sempre perguntava: "Por onde anda ela?". Tem 59 anos e é casada. Não tem filhos. Estudou até a quarta série do ensino fundamental; é natural de lgarassu e mora no mesmo município, com o marido. Não tem pais vivos. Vem diariamente ao Recife para comercializar frutas da região (macaíba, carambola, jenipapo, laranja da terra) e confecciona lambedor de macaíba. Atua na Rua da Praia, no bairro de Santo Antônio.

\section{Quitandeira 03}

"Dona Ni", uma senhora magra, muito ágil e falante para sua idade. Sua primeira fala é sobre a desilusão com os sete filhos, dos quais se queixa de abandono "Se soubesse, não tinha filhos, a gente faz um sacrifício danado e depois eles vão tudo embora". Ni tem uma visão muito aguçada sobre o entorno que a cerca na Praça Dom Vital, e mostra muita precaução ao falar sobre os temas que envolvem a violência urbana na área. Tem 65 anos e é viúva. Não é 
alfabetizada, trabalha na rua desde os oito anos de idade. Natural de Recife, mora atualmente no Engenho Maranguape. Não tem pais vivos. Comercializa hortaliças diferenciadas (pimentões vermelhos, berinjelas e alho porró). Atua na Praça Dom Vital, na lateral do Mercado, no bairro de São José.

\section{Quitandeira 04}

"Galega da Tapioca", morena de gestos calmos, de fala definida, muito ágil no manuseio dos insumos e equipamentos no preparo das tapiocas que serve. Aparenta uma boa visão empresarial, possuindo planos de expansão e noções de investimentos. Tem 44 anos, é divorciada, sem filhos. Cursou o ensino médio completo, trabalha no comércio de comida de rua há oito anos, sempre neste ponto. É natural de Altinho, interior de Pernambuco e mora no bairro de San Martin, sozinha. Os pais moram perto e ela os ajuda eventualmente. Produz e comercializa tapiocas na Rua da Praia, no bairro de Santo Antônio.

\section{Quitandeira 05}

"Nega", uma senhorinha miúda e de olhos argutos, movimenta-se com agilidade entre as panelas de seu carrinho. No primeiro momento do contato mostrou-se desconfiada, sem querer muita conversa, já que estávamos na hora de seu maior movimento. Depois de algumas garfadas dadas por esta pesquisadora em suas preparações, seguida de elogios à sua comida, a conversa fluiu e ela discorreu sobre sua vida e me apresentou aos seus clientes, espalhados pela calçada da Rua de São Pedro. Tem 58 anos, é viúva, tem três filhos e sete netos. Perdeu um dos filhos com 34 anos. Mora com um filho de 33 anos que a ajuda no transporte da barraca diariamente e depende financeiramente dela. Há dois anos produz e comercializa comida de rua por conta própria. É natural do Recife e mora no bairro do lbura. Não é alfabetizada, pois trabalha desde os oito anos de idade na produção e comercialização de alimentos. Atualmente produz e comercializa pratos feitos de almoço na Rua de São Pedro, no bairro de Santo Antônio.

\section{Quitandeira 06}

"Professora" tem 60 anos, é viúva e mora com um filho de 28 anos, do qual depende financeiramente. É amiga da Quitandeira 05 e a ajuda sempre que é preciso, pois sua atuação é esporádica. É natural de Recife e mora em Jaboatão dos Guararapes. Cursou o ensino médio completo (magistério) e atuou como professora no ensino fundamental. Já foi 
empresária no ramo de alimentação diet, mas desistiu por não gostar de cozinhar. Atua na Rua de São Pedro, no bairro de Santo Antônio.

\section{Quitandeira 07}

"Irmã" tem 49 anos, é divorciada e mora com um companheiro. Tem quatro filhos do primeiro casamento. É irmã da Quitandeira 05 e a ajuda quando está em boas condições de saúde, visto que se queixa de dores de cabeça e dores musculares frequentes. É natural do Recife e mora no bairro de Torrões. Cursou a terceira série do ensino fundamental. Produz e comercializa pratos feitos de almoço na Rua de São Pedro, no bairro de Santo Antônio.

\section{Quitandeira 08}

"Rainha da Coxinha" tem 43 anos, é divorciada, tem dois filhos: um rapaz de 21 e uma moça de 18 anos que mora e trabalha com ela. É natural de Recife e mora em Jaboatão dos Guararapes, na divisa com a cidade de Moreno. Cursou até terceira série do ensino fundamental. Comercializa sanduíches e coxinhas de frango, água, refrigerantes e balas. Atua na Rua de São Pedro, no bairro de Santo Antônio.

\section{Família, Gênero, Classe e Raça}

Antropologicamente, a família conceituou-se a partir de estruturas parentais, filiações e representações tribais. Tais referendos deram subsídios para Marx (1973) entender em que condições se estabelecem o modo capitalista de produção e para Engels (1981) buscar a origem da formação familiar e suas mudanças na estruturação da sociedade. Na contemporaneidade, Bruschini (1990, p.31) alerta para a naturalização da família, "o primeiro passo para estudar a família deveria ser o de dissolver sua aparência de naturalidade, percebendo-a como criação humana mutável". Para a (FIBGE, 2004, p.398). "família ou arranjo familiar é o conjunto de pessoas ligadas por laços de parentesco, dependência doméstica ou normas de convivência, residente na mesma unidade domiciliar, ou pessoa que mora só em uma unidade domiciliar"

Estudos sobre família, gênero e trabalho, destacam que a inserção feminina no universo do trabalho remunerado possibilitou significativas mudanças sociais e ruptura de paradigmas que se refletem na configuração familiar contemporânea, apresentando um número significativo de famílias chefiadas por mulheres com aumento significativo destas. De acordo com o IBGE (2010), quando a família é composta por dois cônjuges com filhos, as mulheres representam $22,7 \%$ da chefia destas famílias; já quando apenas um dos pais vive com os dependentes, as mulheres traduzem-se como chefes em $87,4 \%$ dos lares. Isso traz um universo significativo de 
famílias chefiadas por mulheres, as famílias parentais femininas, que, segundo Brito (2008, p.1) está definida como "o grupo familiar é composto pela mulher mãe e seus filhos menores de 25 anos e solteiros. Nesse arranjo familiar, geralmente, é a mulher a única responsável pela sustentabilidade econômica da família".

Entretanto tais mudanças não trazem apenas progresso, carregam também em seu bojo atrasos. Se por um lado é intenso e constante o aumento da mão-de-obra feminina no mercado de trabalho desde meados dos anos 1970, por outro lado existe o elevado desemprego e ou a má qualidade do emprego feminino. Enquanto uma parcela de mulheres tem acesso a empregos de prestígio e cargos de direção por parte de mulheres com alto grau de escolaridade, de outro encontra-se em número significativo do trabalhadoras em atividades precárias e informais tais como o das mulheres que compõem o corpus desta pesquisa.

Em "Trabalho e gênero no brasil nos últimos dez anos" Bruschini (2007, p. 537) apresenta o perfil feminino da atualidade das trabalhadoras, marcado por mulheres com idade mais avançada, casadas e mães revelando uma identidade feminina, voltada dividindo-se entre o trabalho e a família. "A permanência da responsabilidade feminina pelos afazeres domésticos e cuidados com os filhos e outros familiares indica a continuidade de modelos familiares tradicionais, que sobrecarregam as novas trabalhadoras."

Não é intenção deste trabalho aprofundar o debate acerca das relações de trabalho nos domicílios, seus desdobramentos acerca dos movimentos e conquistas feministas, poder-se-á aprofundar estas temáticas em Teixeira (2016) e Leão (2017).

Nesta pesquisa, em um universo de oito entrevistadas, seis delas são chefes de suas famílias; apenas uma está casada, uma é viúva e tem uma relação de dependência e mora com o filho. Dentre as separadas, uma vive com outro companheiro que não é o primeiro marido e pai de seus filhos. As demais cinco entrevistadas são separadas ou viúvas e não dividem a vida com um parceiro fixo.

Destas, dois vivem com filhos em casa, uma com uma filha de 18 anos, a Rainha da Coxinha: "eu trabalho para mim, ela trabalha para ela" ... "quando ela não pode vir trabalhar, eu tomo conta das vendas dela". A quitandeira em questão administra eventualmente duas barracas: a sua própria, de coxinhas e sanduíches, e a da filha de 21 anos, de venda de óculos, e que cursa o ensino fundamental. A outra quitandeira viúva mora com um filho de 33 anos, sendo que ambos os filhos aparentam manter uma relação de dependência financeira para com as mães.

De acordo com Pacheco (2005), o fato de serem responsáveis pelo sustento da casa, sem a presença da figura masculina, sobrecarrega a mulher pobre e chefe de família, exigindo 
das crianças uma participação no mercado de trabalho, acarretando um prejuízo para sua educação, fato encontrado em depoimentos de algumas quitandeiras, que precisaram iniciar sua jornada de trabalho ainda na primeira infância. Para Barros et al. (1994), a participação das crianças nas responsabilidades da casa e no trabalho remunerado as impede de ter tempo e disponibilidade aos estudos, em consequência, tendo menos permanência no sistema educacional, apresentando atrasos e altos índices de evasão escolar.

Entender as relações de vizinhança no meio de comunidades de baixa renda possibilita entender como mulheres se articulam em redes de cooperação, viabilizando suas atividades laborais fora do lar.

Uma das estratégias de sobrevivência das famílias pobres era a circulação das crianças entre a casa da família e de outros parentes e vizinhos. Embora o cuidado das crianças coubesse à mulher - conforme a divisão tradicional do trabalho -, essa mulher não era necessariamente a mãe biológica. Os parentes consanguíneos tinham um papel muito importante na composição das redes de mútua ajuda, onde as lealdades eram fortes e duradouras e contrastavam com a precariedade do laço conjugal. (PACHECO 2005, p. 62)

Quando perguntadas sobre a convivência com os vizinhos, as quitandeiras entrevistadas declaram não ter vínculos fortes com eles, talvez por, em sua maioria, não estarem inseridas na faixa de idade de terem filhos pequenos, comumente entre os 18 e 30 anos, fase em que se necessita de apoio para ausentarem-se do lar para exercerem atividades de ganho financeiro.

De todos os fatores relacionados à esfera reprodutiva, a presença de filhos pequenos é aquele que mais dificulta a atividade produtiva feminina, na medida em que o cuidado com os filhos é uma das atividades que mais consome o tempo de trabalho doméstico das mulheres. As mães dedicam a estas atividades quase 32 horas do seu tempo semanal, um número muito superior ao da média feminina geral e mais ainda ao das mulheres que não tiveram filhos." (BRUSCHINI, 2007, p.545/546).

De acordo com Bruschini, (2007) a responsabilidade em prover e cuidar dos filhos e dos parentes idosos pode ser um dificultador significativo da inserção e permanência feminina no mercado de trabalho.

Uma delas afirma ter bom relacionamento com os vizinhos: "Tenho vizinhos, me dou bem com meus vizinhos", mas que não os frequenta: "Não, quando saio daqui vou para a igreja", e de ter tido um conflito sobre limites de moradia ... "O problema é que tem uma vizinha que aperreia, porque eu ganhei a causa de um muro no terreno".

Elas alegam ainda ter uma jornada de trabalho longa durante a semana, e que de forma geral procuram descansar, ir à igreja, à praia e limpar suas casas ao fim da semana. Algumas relatam reunirem-se com os filhos em datas festivas. 
O processo de separação e/ou de viuvez possibilitou a estas mulheres descobrirem potencialidades e competências relativas ao exercício de atividades rentáveis que proporcionam o seu sustento e de parte de suas famílias. Essa autonomia financeira, acreditase, pode trazer uma autopercepção mais positiva enquanto sujeitos protagonistas de suas próprias histórias.

\section{CONSIDERAÇÕES FINAIS}

A partir do contato com as quitandeiras entrevistadas, este estudo pôde conhecer parte do todo vivenciado pelas atrizes sociais objeto de interesse desta pesquisa.

Visitar o passado, enxergar o presente, buscando construir um futuro, assim como Sette (1948) ressignificou o ato de arruar, esta pesquisa debruçou-se sobre o universo laboral feminino no segmento da alimentação, buscando também o ressignificar do papel da mulher, quitandeira contemporânea, que arrua nos sítios históricos recifenses.

Esta pesquisa trouxe a face de mulheres nem tão jovens, mas que apresentam uma disposição e força de trabalho cotidiano, impensáveis em suas faixas etárias e nas condições adversas que as ruas lhes oferecem.

Encontraram-se mulheres com pouca escolaridade, mas plenas em sabedorias populares e maturidades que a vivência nas ruas Ihes proporcionou. Sabedorias de saber calar como forma de driblar a pouca segurança, sabedorias ao alinhavar acordos que lhes garantam a permanência nestas mesmas ruas, perpetuando, assim, um ciclo de dominação feminina.

Espera-se que ao trazer luz a estas personagens urbanas, retratadas em seus cotidianos, possam-se abrir perspectivas que Ihes possibilitem uma maior visibilidade social e econômica.

A histórica invisibilidade feminina, vislumbrada inicialmente, traduz-se ainda na contemporaneidade, na medida em que os dados mais recentes levantados pelas secretarias que tratam do controle e disciplina do uso e ocupação do solo, bem como da mobilidade urbana, não sentem a necessidade de conhecer de que forma são ocupados os espaços urbanos, as vias públicas, quanto aos números que se perfazem com a presença feminina. $A$ 
ausência deste percentual pode impactar de forma significativa nos programas e dimensionamentos dos espaços a serem projetados arquitetonicamente, a serem entregues aos homens e mulheres ambulantes que atuam no contexto estudado.

O perfil socioeconômico encontrado traz algumas lacunas, por se perceber certa relutância em compartilhamento das informações fidedignas, não se podendo afirmar o real motivo de tal receio. Os cotidianos laborais afiguraram-se um pouco mais estafantes do que se supunha, com jornadas de trabalho longas em circunstâncias de muito pouco conforto e segurança. Percebe-se que a rua e a via pública são ainda espaços destinados aos fortes, e, nesta medida, é surpreendente encontrar estas quitandeiras em sua aparente fragilidade, atuando e demarcando espaços, cada uma a seu modo, costurando e articulando suas estratégias de sobrevivência.

O aspecto mais positivo encontrado nesta pesquisa se deve à percepção da importância que os ganhos e vivências laborais, possibilita a estas mulheres uma autonomia financeira, impensada em momentos históricos da relação feminina com o trabalho fora do lar. A maioria significativa das entrevistadas está inserida na qualidade de gestora do seu próprio negócio; algumas demonstram, inclusive, controle sobre os modos de produção e noções de higiene e segurança alimentar na distribuição dos alimentos.

Esta pesquisa não pretende esgotar o tema, tampouco trazer certezas sobre o universo feminino. A importância deste trabalho se dá na medida em que se procura trazer à toa aspectos da vida cotidiana vivenciada por estas mulheres, as quitandeiras urbanas, em apresentar um recorte de suas vidas familiares, seus sonhos, suas histórias e seu trabalho.

As informações captadas em entrevistas e conversas buscaram retratar uma realidade que se supõe difícil sob vários aspectos. Entende-se que nem sempre os dados relatados condizem com a realidade impressa e registrada cotidianamente em periódicos e em pesquisas governamentais. Entretanto, a apreensão destas informações possibilita iniciar uma sistematização de pensamento voltado a visibilizar a mulher que é pobre, urbana, pernambucana e que atua na alimentação, um segmento de significativas representações culturais e gerador de cifras milionárias.

Não é intenção de esta pesquisadora criar generalizações a partir dos dados obtidos. Acredita-se, entretanto, que o conteúdo verbalizado e retratado das condições socioeconômicas destas mulheres entrevistadas permitiu apreender a realidade que esta pesquisa julga ser ponto de convergência, vivenciada por outras mulheres em situações semelhantes. 


\section{REFERÊNCIAS}

ALVES, Zélia Mana Mendes Biasoli; SILVA, Maria Helena G. F. Dias da. Análise qualitativa de dados de entrevista: uma proposta. Paidéia (Ribeirão Preto) n. 2, Ribeirão Preto, Feb./July 1992. Disponível em: http://www.scielo.br/scielo.php?script=sci_arttext\&pid=S0103863X1992000200007. Acesso em: 20 ago. 2017.

BARDIN, Laurence. Análise de Conteúdo. São Paulo: Edições 70, 1979.

BECKER, Howard. Métodos de pesquisa em ciências sociais. 2.ed. São Paulo: Hucitec, 1994.

BONOMO, Juliana Resende. 0 tabuleiro afro-brasileiro: 0 abastecimento alimentar e a resistência das quitandeiras negras no Brasil do século XVIII, 2014. Disponível em: http://www.encontro2014.sp.anpuh.org/esso. Acesso em: 27 out. 2015.

BOURDIEU, Pierre. Espace social et sés transformations. In: La distinction: critique sociale Du jugement. Paris Minuit, 1979.

BRASIL. Ministério do Trabalho. 1978. Disponível em: www.pncq.org.br/uploads /2016/NR_MTE/NR. 20PPRA.pdf. Acesso em 3 ago. 2018.

BRAUDEL, Fernand. Civilização material, economia e capitalismo séculos XV-XVII - Os Jogos das Trocas. Volume 2. São Paulo, Martins Fontes, 1996.

BRITO, Flavio dos Santos. Mulher chefe de família: um estudo de gênero sobre a família monoparental feminina. Revista Urutágua. N 15- abr-jul,2008.

BRUSCHINI Maria Cristina Aranha. Mulher, casa e família cotidiano nas camadas médias paulistanas. São Paulo: Revista dos Tribunais, 1990.

BRUSCHINI, Maria Cristina Aranha. Trabalho e gênero no Brasil nos últimos dez anos. Cadernos de pesquisa, v. 37, № 132, p. 537-572, set/dez 2007. Disponível em: http://www.scielo.br/pdf/cp/v37n132/a0337132. Acesso em 14/04/2020.

DIAS, Maria Odila Leite da Silva. Quotidiano e poder em São Paulo no século XIX. São Paulo: Brasiliense, 1984.

DINIZ, Débora; GUERREIRO, lara Coelho Zito. Ética na Pesquisa Social: Desafios ao Modelo Biomédico, 2008. Disponível em: www.reciis. cict.fiocruz.br. Acesso em: 20 jul. 2018.

DURHAM, Eunice. Família e Reprodução Humana. In: Perspectivas antropológicas da mulher, 3. Rio de Janeiro, Zahar, 1983.

ENGELS, Friedrich. A origem da família, da Propriedade e do Estado. 6. ed. Rio de Janeiro: Civilização Brasileira, 1981. 
FERNANDES, Maria Esther. Memória Camponesa. Anais da 21a Reunião Anual de Psicologia, SPRP, Ribeirão Preto, 1991.

FREYRE, Gilberto. Casa-Grande \& Senzala: Formação da família brasileira sob o regime da economia patriarcal. 48. ed. Recife: Global, 2003.

GIL, Antônio Carlos. Métodos e técnicas de pesquisa social. 5.ed. São Paulo: Atlas, 1999.

GODOY, Arilda Schmidt. Pesquisa qualitativa - tipos fundamentais. Revista de Administração de Empresas, v. 35, n. 3, p. 20-29, 1995.

GOMES, Almirava Ferraz. O perfil empreendedor de mulheres que conduzem seu próprio negócio: um estudo na cidade de Vitória da Conquista - BA. Revista Alcance - UNIVALI - Vol. 11 - n.2 p. 207 - 226 - maio/ago. 2004.

GOULART, José Alípio. O mascate no Brasil. Rio de Janeiro: Editora Conquista, 1967. (Coleção Terra dos Papagaios).

IBGE. Instituto Brasileiro de Geografia e Estatística, 2015. Disponível em: http://www.ibge.gov.br/home/. Acesso em: 1 nov. 2015.

LEÃO, Natalia; CANDIDO, Marcia Rangel; CAMPOS, Luiz Augusto; JÚNIOR. João Feres, 2017. Disponível em: http://gemaa.iesp.uerj.br/relatorios/relatorio-das-desigualdades-gemaano-1/

MARX, Karl. Formações Econômicas Pré-Capitalistas. Lisboa: Estampa 1973.

MARX, Karl. Introdução à contribuição para a crítica da economia política. Lisboa: Estampa, 1973.

MINAYO, Maria Cecília de Souza. Pesquisa Social: Teoria, Método e Criatividade. 21. ed. Petrópolis: Vozes, 2002.

NÓBREGA, Maria de Lourdes Carneiro da Cunha. Todo caminho dá na venda: a influência do comércio de varejo nas transformações físicas do espaço urbano. Os bairros do Recife, Santo Antônio e São José. 1970-2006. Tese (Doutorado em Arquitetura e Urbanismo) - Universidade Federal de Pernambuco. Faculdade de Arquitetura e Urbanismo. Pernambuco, 2008.

PACHECO, Ana Lúcia Paes de Barros. Mulheres pobres e chefes de família. Rio de Janeiro, 2005. Tese (Doutorado em Psicossociologia de Comunidades e Ecologia Social), UFRJ/IP; EICOS, 2005.

PANTOJA, Selma Alves. Da kitanda à quitanda. Revista de História. Disponível em: http://www.revistadehistoria.com.br/secao/artigos-revista/da-kitanda-a-quitanda 9/122/2008. Acesso em: 23 abr. 2016. 
RICHARDSON, Roberto Jarry. Pesquisa social: métodos e técnicas. 3. ed. São Paulo: Atlas, 2012.

SETTE, Mário. Arruar, História pitoresca do Recife Antigo. Rio de Janeiro: Casa do Estudante, 1948.

TEIXEIRA, Tatiana Silva; BIFANO, Amélia Carla Sobrinho; LOPES, Maria de Fátima. Trabalho doméstico: reprodução e resistência. Oikos: Família e Sociedade em Debate, v. 27, n. 1, p. 59-78, 24 jun. 2016.

WADI, Yonissa Marmitt. "Palácio para guardar doidos": uma história das lutas pela construção do hospital de alienados e da psiquiatria no Rio Grande do Sul. Dissertação (Mestrado). Programa de Pós-Graduação em História UFRGS, 1997. 